\title{
10 Scaling climate-smart agriculture for agricultural transformation in Southern Africa
}

\author{
Caroline Mwongera, Christine Lamanna, \\ Hannah N. Kamau and Evan Girvetz
}

\section{Climate change and agriculture in Southern Africa}

Agriculture accounts for more than 20\% of the Gross Domestic Products (GDP) of most African countries (Awokuse and Xie, 2015), supporting over $80 \%$ of the rural population (Davis et al., 2017). Sub-Saharan Africa is the region most affected by undernourishment and with the greatest food security risk because of the uncertainties of climate change, land degradation and market fluctuations (Gebbers and Adamchuk, 2010; Ramirez-Villegas and Thornton, 2015; van Ittersum et al., 2013) and a doubling of the population by 2050 . Average temperatures have warmed by nearly $0.5^{\circ} \mathrm{C}$ over the last century and are projected to increase a further $1.4-5.5^{\circ} \mathrm{C}$. by 2100 (Adhikari et al., 2015). More troubling for the large proportion of the population that depends on rain-fed agriculture, is the projected increase in variability of precipitation cycles across the continent. Although median precipitation is projected to change by only $-2 \%$ to $20 \%$ on average, this change will be accompanied by increased variability in the onset and duration of rainy seasons and increased intensity of both rainfall events and dry spells. Local climate projections in southern Africa predict an increase in mean annual temperatures from about $1.5^{\circ} \mathrm{C}$ to $4^{\circ} \mathrm{C}$ (Zinyengere and Crespo, 2017) and a general drying over the region (IPCC, 2014; Zinyengere et al., 2013). Thus, there is a dire need for agriculture in Southern Africa to transform from its current climate-vulnerable state to a state that is sustainably food secure in the face of climate change.

One proposed solution to the intertwined problems of food insecurity and climate change is Climate-Smart Agriculture (CSA). CSA is an approach to agricultural transformation seeking to 1) sustainably increase agricultural productivity; 2) adapt and build resilience to climate change; and 3) reduce or remove greenhouse gas (GHG) emissions where possible (FAO, 2013). CSA is not a prescriptive set of agricultural practices or technologies but rather endorses locally relevant innovations that meet the three goals of productivity, resilience and mitigation. The popularity of CSA in Africa is evident. In 2014, the African Union endorsed the "Vision $25 \times 25$ ", of having at least 25 million smallholder farming households practicing CSA by 2025. More so, 42 African 
countries prioritize adaptation in the agriculture sector in their Nationally Determined Contributions (NDCs) to the 2015 Paris Climate Agreement (AfDB, 2019), while 29 specifically mention CSA in their NDCs (Richards et al., 2015).

Given the political will and resources behind scaling CSA in Southern Africa, does the approach have the potential to transform agriculture for sustainable food security in the region? Here we give a brief overview of CSA initiatives in the region, make the case for CSA contributing to agricultural transformation and give recommendations for policymakers for up-scaling CSA in Southern Africa based on experiences in the region and elsewhere.

\section{Methodology}

To assess the potential for CSA to transform agriculture in Southern Africa, we draw on three key resources for the region: the Evidence for Resilient Agriculture (ERA) database, the CSA Country Profiles and the CCARDESA SAAIKS Knowledge Hub. The ERA, formerly referred to as CSA compendium, is a platform designed to pinpoint what agricultural technologies work and in which locations. It is a systematic review of the English language peer-reviewed literature using search terms related to more than 70 potential CSA practices and 20 outcomes related to the three pillars of CSA (Rosenstock et al., 2015, World Agroforestry, 2019). For inclusion in the resulting meta-analysis, a study had to include at least one potential CSA practice, have a relevant non-CSA control, provide quantitative data on at least one CSA outcome and have taken place within Africa.

The CSA Country Profiles are participatory appraisals of the agricultural challenges in countries and how CSA can help to adapt and mitigate climate change. At their core is an empirical assessment of potential CSA technologies through consultation with 40-50 country-level experts. Each CSA country profile is framed around six key analytical stages: 1) relevance of agriculture in the country; 2) challenges for the agricultural sector; 3) climate change impacts on agriculture; 4) CSA technologies and practices; 5) institutions and policies for CSA; and 6) financing CSA. The paper uses data from the profiles of five Southern Africa countries developed so far: Lesotho, Malawi, Mozambique, Zambia and Zimbabwe. CSA country profiles are a project of the International Center for Tropical Agriculture (CIAT) in collaboration with the CGIAR Research Program on Climate Change, Agriculture and Food Security (CCAFS), the World Bank and the UK Government's Department for International Development (DFID).

The CCARDESA SSAIKS Knowledge Hub is a repository of agricultural research and extension information for the Southern Africa region, maintained by the Center for Coordination of Agricultural Research and Development in Southern Africa (CCARDESA). It currently contains nearly 400 publications on CSA in the region, including research outputs, policy briefs, extension materials and decision-support tools. 


\section{What is the evidence base for CSA in Southern Africa?}

In Southern Africa, there is a wealth of evidence available on CSA. Based on the Evidence for Resilient Agriculture systematic review, there are approximately 500 studies of potential CSA technologies in the Southern Africa region. While the region includes diverse production systems, nearly $50 \%$ of the available data focuses on maize, while 10\% deals with legumes (Figure 10.1). Thus, much is known about the impact of CSA in maize systems, but very little is known about the impact of CSA on other economically and nutritionally important crops such as sorghum, dairy or vegetables. More than 70 individual CSA practices have been documented in the region, with addition of inorganic fertilizers being the most common practice studied, followed by mulching and reduced tillage, both of which are components of conservation agriculture, reflecting the long history of the practice in the region.

The participatory CSA Country Profiles identified 61 climate-smart technologies ranging across crop, agroforestry, livestock, soil and water management and energy systems for the 22 production systems selected across the five Southern African countries. Thirty eight percent of the total value chains selected were livestock, followed by pulses and cereals (19\%), roots and tubers $(14 \%)$ and oilseed (10\%). In each of the production systems, experts identified the most appropriate technologies and scored them on a point scale of -10 to +10 for climate-smartness based on their contribution to productivity, adaptation and mitigation. The long list of practices for each production system had an average of ten technologies. Based on the average climate smartness scores, Figure 10.2 presents the top three CSA technologies identified in the 22 production systems across five countries. This reveals the expansive array of already tested CSA technologies suited to Africa's diverse production systems and regions (Sova et al., 2018) and available for scaling to reach a wide number of farmers. Yet, the current overall rate of CSA adoption by farmers remains low despite their benefits (Mwongera et al., 2015; Senyolo et al., 2018). For instance, although conservation agriculture, water conservation, drought tolerant and early maturing varieties are most suited climate-smart agriculture technologies to cope with water stress in Southern Africa, high initial investment costs and additional labour requirements limit their adoption (Senyolo et al., 2018). However, farmers in sub-Saharan Africa are already putting CSA into action and increasingly adopting some of these technologies.

\section{CSA as agricultural transformation: examples from the field}

Many improved agricultural practices have the potential to achieve both the three goals of CSA (improved productivity, increased resilience to climate change and mitigation of greenhouse gases) as well as agricultural transformation to sustainable food security. Conservation agriculture (CA), or the practice of minimizing tillage, maintaining soil cover and diversifying crop production, 

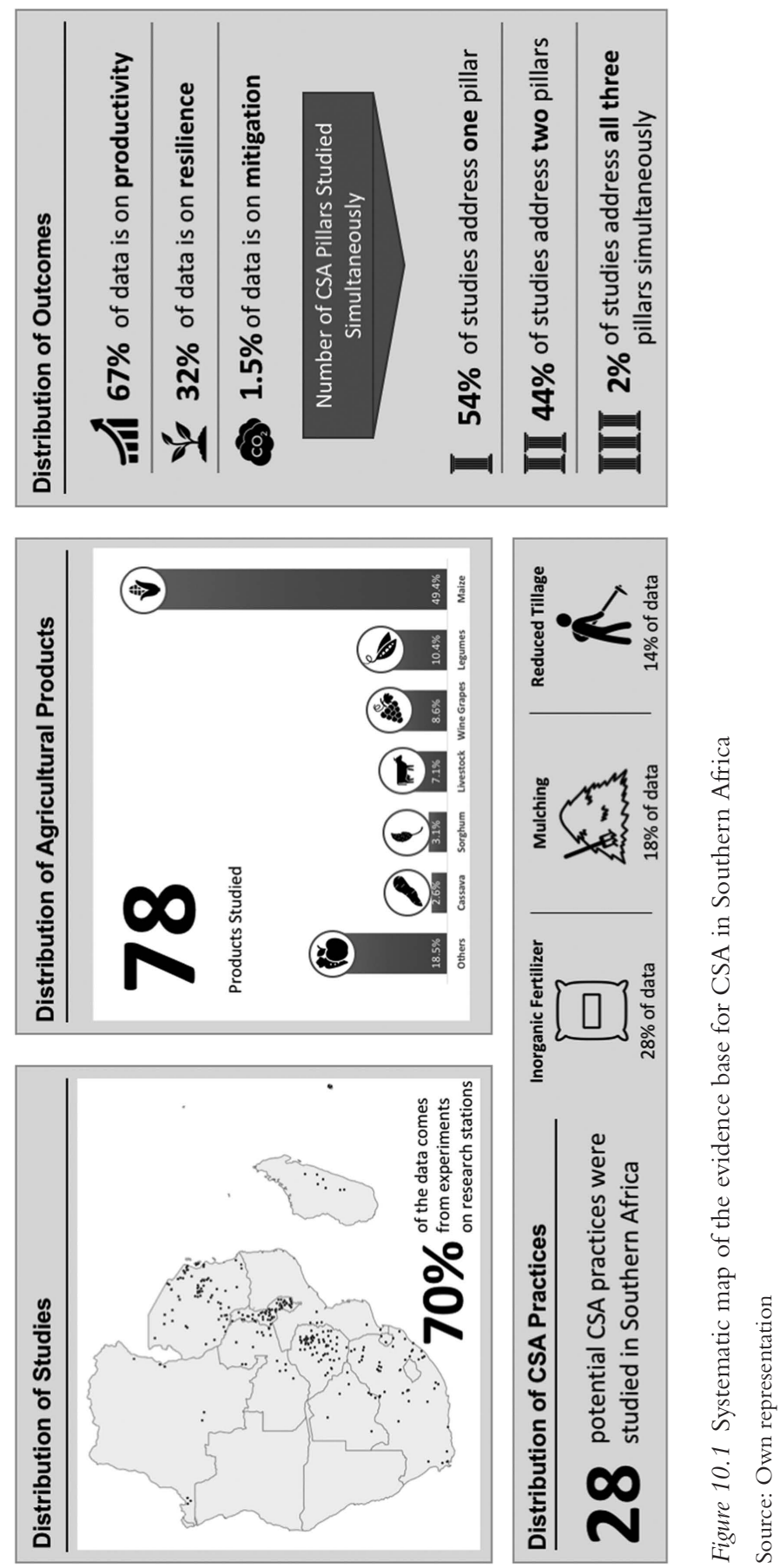


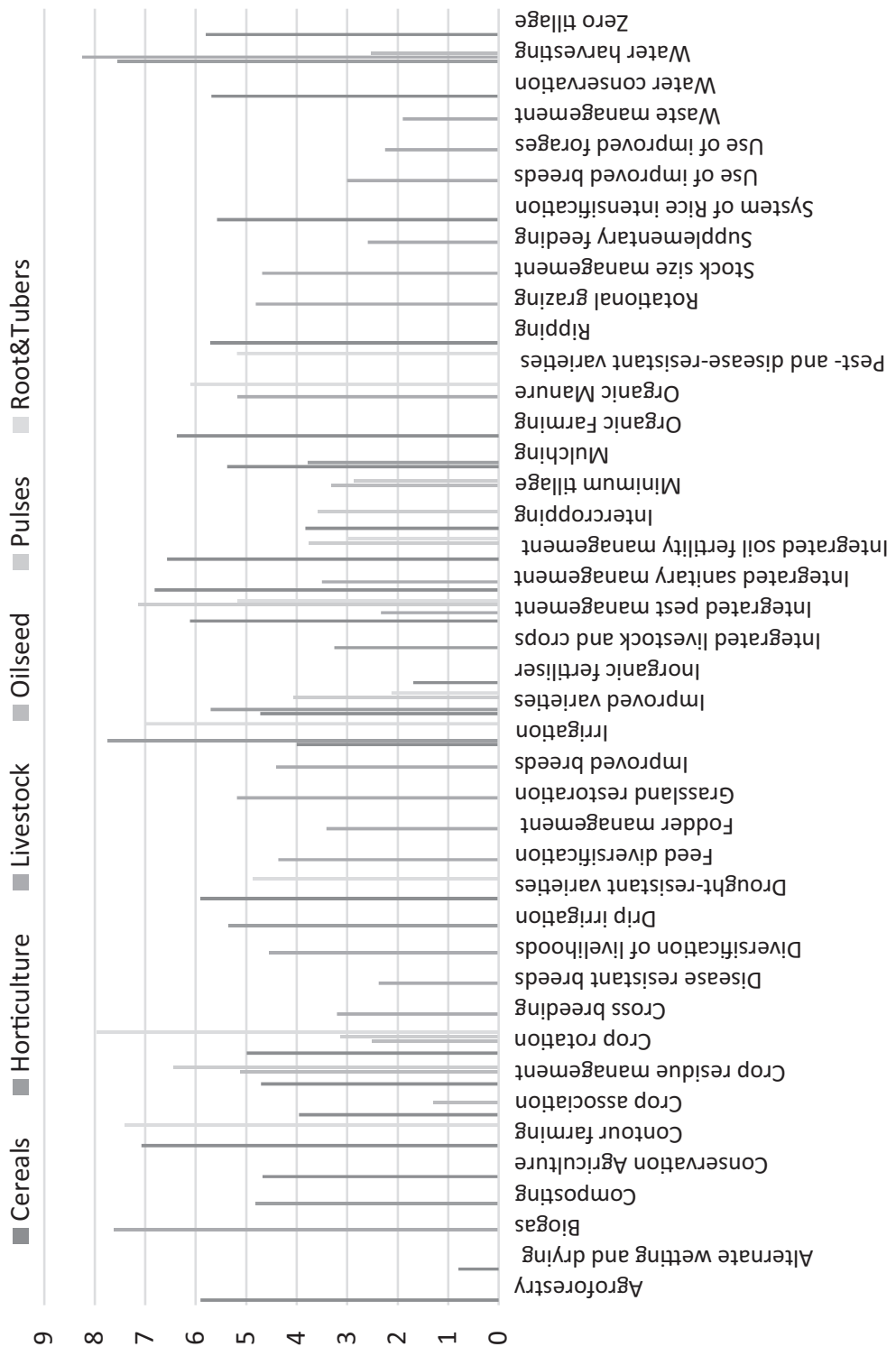

ssəuұлеus әұеш!) 
has been shown to increase productivity of crops such as maize, particularly in drier areas such as Southern Africa (Pittelkow et al., 2015). In Malawi, conservation agriculture increased the resilience of maize systems to drought events by maintaining a higher yield during an El Niño event than conventional agricultural systems (Steward et al., 2019). While mitigation benefits from CA through increases in soil carbon may be modest (Theirfelder et al., 2017), in Tanzania, increased productivity of maize under conservation agriculture reduced the emissions intensity of maize production (GHGs produced per unit of yield), resulting in net mitigation benefits from CA (Kimaro et al., 2015). Thus, conservation agriculture has the potential increase sustainable food security, particularly in drier cereal production systems in the region.

Agroforestry, or incorporating trees into crop and livestock systems, is another commonly promoted approach in the region with the potential to deliver on CSA goals and agricultural transformation. For example in semi-arid Tanzania, intercropping maize with Cajanus cajan resulted in higher total yield than maize monocropping alone (LER $=1.46)$, particularly in lower productivity regions (Kimaro et al., 2019). The inclusion of trees into cropping systems can modify the microclimate through shading and hydraulic lift, as well as increase soil health through nitrogen fixation (in the case of leguminous "fertilizer trees") and deposition of organic material, resulting in lower moisture stress for crops. For example, in Zambia, intercropping Leucaena leucocephala with maize resulted in higher rain-use efficiency of the maize crop and buffered against yield losses in dry years (Sileshi et al., 2011). Finally, agroforestry has direct mitigation benefits, through the capture and storage of carbon on the landscape. Indeed, it is estimated that trees in agricultural lands accounts for more than $75 \%$ of the carbon stored in this land-use globally (Zomer et al., 2016).

\section{Scaling-up CSA in Southern Africa: recommendations for policymakers}

In order to realize the benefits of CSA for achieving agricultural transformation in Southern Africa, it must be scaled-up from case-studies to a common approach to agriculture in the region. In order to achieve scaling for CSA, the following are seven key recommendations for policymakers.

\section{Prioritizing climate-smart agriculture investments}

Economic, technical, social considerations and priority goals of stakeholders vary and require to be considered in the selection of the portfolio of CSA technologies (Andrieu et al., 2017; Mwongera et al., 2015). Given the broad range of CSA technologies available and the multiple dimensions of CSA, identifying appropriate interventions requires prioritizing what is appropriate for given contexts. Site-specific CSA options that are gender responsive are likely to provide lasting benefits, especially for women, youth, ethnic minorities and the very poor farmers at the community. 
2 Moving beyond a single farm to landscapes

A recent global review notes a shift from a technology-oriented approach to a more system-oriented approach that considers the complexity of farming systems (Totin et al., 2018). Climate change is part of the wider set of interacting social, economic, political and cultural dimensions within and beyond a single farm, implying that a more integrated landscape approach is needed to move farmers towards a sustainable and resilient livelihood. This comprehensive approach stimulates potential synergies and sustainable transformation in complex systems (Hounkonnou et al., 2012), such as those found in Africa. Developing responses to climate change through climate-smart agriculture thus requires, for example, integrating market, political and other institutional aspects that shape the context in which farming takes place. Across larger landscapes, impacts need to be assessed for their sustainability.

3 Ensuring CSA is mainstreamed into agricultural programmes

For CSA to be scaled out to establish transformational change within agriculture systems, large-scale systematic investment is needed. There are bottlenecks in mainstreaming climate-smart agriculture in Africa which include weak governance, institutional arrangements and linkages between relevant sectors, e.g., energy, environment, climate, water, agriculture and forestry. Often this contributes to lack of a coordinated policy mix and response to climate change at the subnational and national levels (Ampaire et al., 2017). Linking national priority needs and investments with subnational level experiences and ensuring CSA is incorporated into broader policy and strategy processes provides enabling conditions for CSA implementation. Most importantly, local institutions should be strengthened to improve CSA policy coherence and effective implementation at subnational levels (FAO, 2010).

4 Capacity development for up scaling CSA

The gap between awareness and use of CSA technologies is one of the challenges of shifting from CSA theory to practice. Second, CSA evidence focuses disproportionately on the main agricultural production systems in the Southern African region. Access to training and information, technology transfer and technological capabilities (Martinez-Baron et al., 2018) are some of the key elements required. Strengthening the capacity of key stakeholders (farmers, CSA implementers, researchers, policymakers) through training and information dissemination, identifying and testing, in a participatory manner, the best CSA practices promotes learning. The use of information and communications technology such as local radios and short message service are supporting the dissemination of the technical information and raising awareness on CSA.

5 Institutions and partnerships

An enabling environment for CSA adoption requires defining and developing partnerships between institutions and organizations supporting 
CSA implementation. Potential synergies can be realized by strategically capitalizing on key institutional structures and networks, participatory processes, social learning and multi-stakeholder negotiation (O'Donnell and Garrick, 2017) for collaboration, access to resources and the dissemination of the technologies. In Africa, private sector support for CSA technologies is still limited, with Government representing the single largest CSArelated institutional category (Sova et al., 2018). The private sector plays an important role in supporting the uptake of CSA technologies for example, market, credit and insurance services.

6 Monitoring and Evaluation

To test and track the changes resulting from CSA implementation, the evidence of how such successes are measured and achieved is of critical importance (Neate, 2013). Gleaning clear empirical messages to inform farmers and policymakers and support any scaling up will depend on continuous two-way feedback mechanisms between multiple stakeholders, e.g., researchers and practitioners, farmers, extension agents and policymakers on the relevance of particular CSA technologies in a given context. The monitoring should effectively track CSA outcomes through meaningful indicators and provide timely information for adaptive management (Eitzinger et al., 2017).

7 CSA financing

It is evident that the investment needed to adapt to climate change and accelerate adoption of CSA needs to be scaled up considerably. Adoption of climate-smart agricultural innovations may also be associated with new challenges in terms of resources to acquiring new inputs, equipment, knowledge, infrastructure, human resources and institutional support. Actions are required from a broad range of stakeholders from government and the public sector, private sector, academia research, nongovernmental organizations and community based organizations. Farmers have limited assets and lack access to affordable financial services to allow them to invest in adopting CSA technologies at scale. There is need to strengthen financial opportunities, agricultural insurance, credits and organize resource flows to create synergies (Williams et al., 2015).

\section{Conclusion}

Considering the urgency of action needed to achieve a $1.5^{\circ} \mathrm{C}$ future, it is essential to promote a type of agriculture that can help small-scale farmers to adapt to climate change while reducing impact on the environment. Climate-smart agriculture practices exist, the focus should be on the dissemination of proven and successful technologies. Further research on the impacts of CSA should include a broader range of economically and nutritionally important production systems such as the small grain cereals (millet, sorghum) roots, tubers, livestock and aquaculture. 


\section{References}

Adhikari, U., Nejadhashemi, A.P. and Woznicki, S.A. (2015) Climate change and eastern Africa: A review of impact on major crops. Food and Energy Security. 4, 110-132.

AfDB. (2019) Analysis of Adaptation Components of Africa's Nationally Determined Contributions (NDCs). African Development Bank, Abidjan, Côte d'Ivoire. 86 p.

Ampaire, E., Acosta, M., Mwongera, C., Läderach, P., Eitzinger, A., Lamanna, C., Mwungu, C., Shikuku, K., Twyman, J. and Winowiecki, L. (2017) Formulate Equitable Climate-Smart Agricultural Policies. International Center for Tropical Agriculture (CIAT), Cali, Colombia. 8 p.

Andrieu, N., Sogoba, B., Zougmore, R., Howland, F., Samake, O., Bonilla-Findji, O., Lizarazo, M., Nowak, A., Dembele, C. and Corner-Dolloff, C. (2017) Prioritizing investments for climate-smart agriculture: Lessons learned from Mali. Agricultural Systems. 154, 13-24. https://doi.org/10.1016/j.agsy.2017.02.008.

Awokuse, T.O. and Xie, R. (2015) Does agriculture really matter for economic growth in developing countries? Canadian Agricultural Economics Society. 63, 77-99. https://doi. org/10.1111/cjag.12038.

Davis, B., Di Giuseppe, S. and Zezza, A. (2017) Are African households (not) leaving agriculture? Patterns of households' income sources in rural Sub-Saharan Africa. Food Policy. 67, 153-174. https://doi.org/10.1016/j.foodpol.2016.09.018.

Eitzinger, A., Mwongera, C., Läderach, P., Acosta, M., Ampaire, E.L., Lamanna, C., Mwungu, C.M., Shikuku, K.M., Twyman, J. and Winowiecki, L.A. (2017) Monitor climate-smart agricultural interventions with a real-time participatory tool. International Center for Tropical Agriculture (CIAT), Cali, Colombia. 6 p.

FAO. (2013) Climate-Smart Agriculture Sourcebook. Food and Agriculture Organization of the United Nations, Rome, Italy. 570 p.

FAO. (2010) "Climate Smart” Agriculture: Policies, Practices and Financing for Food Security. Food and Agriculture Organization of the United Nation, Rome, Italy. 41 p.

Gebbers, R. and Adamchuk, V.I. (2010) Precision agriculture and food security. Science. 327, 828-831. https://doi.org/10.1126/science.1183899.

Hounkonnou, D., Kossou, D., Kuyper, T.W., Leeuwis, C., Nederlof, E.S., Röling, N., SakyiDawson, O., Traoré, M. and van Huis, A. (2012) An innovation systems approach to institutional change: Smallholder development in West Africa. Agricultural Systems. 108, 74-83. https://doi.org/10.1016/j.agsy.2012.01.007.

IPCC. (2014) Climate change 2014: Impacts, adaptation, and vulnerability. In: Field, C.B., Barros, V.R., Dokken, D.J., Mach, K.J., Mastrandrea, M.D., Bilir, T.E., Chatterjee, M., Ebi, K.L., Estrada, Y.O., Genova, R.C., Girma, B., Kissel, E.S., Levy, A.N., MacCracken, S., Mastrandrea, P.R. and White, L.L. (Ed.), Contribution of Working Group II to the Fifth Assessment Report of the Intergovernmental Panel on Climate Change. Cambridge, UK and New York, USA: Cambridge University Press, pp. 1-32.

Kimaro, A.A., Mpanda, M., Rioux, J., Aynekulu, E., Shaba, S., Thiong'o, M., Mutuo, P., Abwanda, S., Shepherd, K., Neufeldt, H. and Rosenstock, T.S. (2015) Is conservation agriculture 'climate-smart' for maize farmers in the highlands of Tanzania? Nutrient Cycling in Agroecosystems. 105, 217-228.

Kimaro, A.A., Sererya, O.G., Matata, P., Uckert, G., Hafner, J., Graef, F., Sieber, S. and Rosenstock, T.S. (2019) Understanding the multidimensionality of climate-smartness: Examples from agroforestry in Tanzania. In: Rosenstock, T.S., Nowak, A. and Girvetz, E. (Eds.), The Climate-Smart Agriculture Papers. Springer International Publishing, pp. 153-162. 
Martinez-Baron, D., Orjuela, G., Renzoni, G., Loboguerrero Rodríguez, A.M. and Prager, S.D. (2018) Small-scale farmers in a $1.5^{\circ} \mathrm{C}$ future: The importance of local social dynamics as an enabling factor for implementation and scaling of climate-smart agriculture. Current Opinion in Environmental Sustainability. 31, 112-119. https://doi.org/10.1016/ j.cosust.2018.02.013.

Mwongera, C., Shikuku, K.M., Winowiecki, L., Twyman, J., Läderach, P., Ampaire, E., van Asten, P. and Twomlow, S. (2015) Climate-Smart Agriculture Rapid Appraisal (CSA-RA): A Prioritization Tool for Outscaling CSA. Step-by-step Guidelines (No. 409). International Center for Tropical Agriculture (CIAT). Cali, Colombia, 44.

Neate, P. (2013) Climate-Smart Agriculture Success Stories from Farming Communities Around the World. Wageningen, Netherlands: CGIAR Research Program on Climate Change, Agriculture and Food Security (CCAFS) and the Technical Centre for Agricultural and Rural Co-operation (CTA), 44.

O'Donnell, E.L. and Garrick, D.E. (2017) Chapter 26 - Defining success: A multicriteria approach to guide evaluation and investment. In: Horne, A.C., Webb, J.A., Stewardson, M.J., Richter, B. and Acreman, M. (Eds.), Water for the Environment. Academic Press, pp. 625-645. https://doi.org/10.1016/B978-0-12-803907-6.00026-7.

Pittelkow, C.M., Liang, X., Linquist, B.A., van Groenigen, K.J., Lee, J., Lundy, M.E., van Gestel, N., Six, J., Venterea, R.T. and van Kessel, C. (2015) Productivity limits and potentials of the principles of conservation agriculture. Nature. 517, 365-368.

Ramirez-Villegas, J. and Thornton, P.K. (2015) Climate Change Impacts on African Crop Production. CGIAR Research Program on Climate Change, Agriculture and Food Security (CCAFS) Working Paper no. 119, Copenhagen, Denmark.

Richards, M., Bruun, T.B., Campbell, B.M., Gregersen, L.E., Huyer, S., Kuntze, V., Madsen, S.T.N., Oldvig, M.B. and Vasileiou, I. (2015) How Countries Plan to Address Agricultural Adaptation and Mitigation: An Analysis of Intended Nationally Determined Contributions. CGIAR Research Program on Climate Change, Agriculture and Food Security (CCAFS) InfoNote.

Rosenstock, T.S., C. Lamanna, S. Chesterman, et al. (2015) The Scientific Basis for ClimateSmart Agriculture: A Systematic Review Protocol. CGIAR Research Program on Climate Change, Agriculture and Food Security (CCAFS) Working Paper no. 138, Copenhagen, Denmark.

Senyolo, M.P., Long, T.B., Blok, V. and Omta, O. (2018) How the characteristics of innovations impact their adoption: An exploration of climate-smart agricultural innovations in South Africa. Journal of Cleaner Production. 172, 3825-3840. https://doi.org/https://doi. org/10.1016/j.jclepro.2017.06.019.

Sileshi, G.W., Akinnifesi, F.K., Ajayi, O.C. and Muys, B. (2011) Integration of legume trees in maize-based cropping systems improves rain use efficiency and yield stability under rain-fed agriculture. Agricultural Water Management. 98, 1364-1372.

Sova, C.A., Grosjean, G., Baedeker, T., Nguyen, T.N., Wallner, M., Jarvis, A., Nowak, A., Corner-Dolloff, C., Girvetz, E. and Laderach, P.M.L. (2018) Bringing the concept of climate-smart agriculture to life: Insights from CSA country profiles across Africa, Asia, and Latin America. https://doi.org/doi:10.1596/31064.

Steward, P.R., Thierfelder, C., Dougill, A.J. and Ligowe, I. (2019) Conservation agriculture enhances resistance of maize to climate stress in a Malawian medium-term trial. Agriculture, Ecosystems \& Environment. 277, 95-104.

Theirfelder, C., Chivenge, P., Mupangwa, W., Rosenstock, T.S., Lamanna, C. and Eyre, J.X. (2017) How climate-smart is conservation agriculture (CA)? It's potential to deliver on 
adaptation, mitigation, and productivity on smallholder farms in southern Africa. Food Security. 9, 537-560.

Totin, E., Segnon, C.A., Schut, M., Affognon, H., Zougmoré, B.R., Rosenstock, T. and Thornton, K.P. (2018) Institutional perspectives of climate-smart agriculture: A systematic literature review. Sustainability. https://doi.org/10.3390/su10061990.

van Ittersum, M.K., Cassman, K.G., Grassini, P., Wolf, J., Tittonell, P. and Hochman, Z. (2013) Yield gap analysis with local to global relevance - A review. Food Crops Research. 143, 4-17. https://doi.org/10.1016/j.fcr.2012.09.009.

Williams, T.O., Mul, M., Cofie, O., Kinyangi, J., Zougmore, R., Wamukoya, G., Nyasimi, M., Mapfumo, P., Speranza, C.I., Amwata, D., Frid-Nielsen, S., Partey, S., Girvetz, E., Rosenstock, T. and Campbell, B.M. (2015) Climate Smart Agriculture in the African Context. Feeding Africa Conference, 21-23 October.

World Agroforestry. (2019) Evidence for resilient agriculture. Database. https://era.ccafs.cgiar.org. Zinyengere, N. and Crespo, O. (2017) Chapter 2 - Assessing local impacts of climate change on crop production in Southern Africa: Critiquing an approach. In: Zinyengere, N., Theodory, T.F., Gebreyes, M. and Speranza, C.I. (Eds.), Beyond Agricultural Impacts. Academic Press, pp. 13-37. https://doi.org/10.1016/B978-0-12-812624-0.00002-8.

Zinyengere, N., Crespo, O. and Hachigonta, S. (2013) Crop response to climate change in Southern Africa: A comprehensive review. Glob. Planet. Change. 111, 118-126. https:// doi.org/10.1016/j.gloplacha.2013.08.010.

Zomer, R.J., Neufeldt, H., Xu, J., Ahrends, A., Bossio, D., Trabucco, A., van Noordwijk, M. and Wang, M. (2016) Global tree cover and biomass carbon on agricultural land: The contribution of agroforestry to global and national carbon budgets. Scientific Reports. 6, 29987. 